\title{
РИСКИ В СИСТЕМЕ УПРАВЛЕНИЯ ПЕРСОНАЛОМ ПРОМЫШЛЕННОЙ ОРГАНИЗАЦИИ
}

\author{
Крюков Алексей Анатольевич \\ АО «Концерн воздушно-космической обороны \\ «Алмаз-Антей» \\ alexeykryukov@yandex.ru
}

RISKS IN THE PERSONNEL MANAGEMENT SYSTEM OF AN INDUSTRIAL ORGANIZATION

Аннотация. Эффективность деятельности хозяйствующих субъектов, согласно современным требованиям управления, обусловливается, главным образом, кадровым потенциалом, квалификацией сотрудников, кадровой политикой предприятия.

Summary. The Efficiency of business entities, according to modern management requirements, is mainly determined by the human resources potential, employee qualifications, and personnel policy of the enterprise.

Full-time employees are an organic element of any enterprise, since it is the person who is the basis of production. Based on this provision, the company's management should take into account all risks directly related to personnel. Risks in personnel management are considered to be the possible probability of losses for the company associated with the activities of the company's personnel.

The article analyzes the most frequent groups of risks and their causes; defines a strategy for minimizing them.

Keywords: enterprise personnel, risks, personnel management, risk minimization.

Штатные работники являются органичным элементом любого предприятия, поскольку именно человек представляет собой основу производства. Исходя из данного положения, руководством предприятия должны учитываться все риски, непосредственно связанные с персоналом. Рисками в управлении персоналом принято считать возможную вероятность убытков для предприятия, связанную с деятельностью персонала предприятия.

В статье проведен анализ наиболее частых групп рисков и причин их в0зникновения; определена стратегия по их минимизированию.

Ключевые слова: персонал предприятия, риски, управление персоналом, минимизация рисков.

Риски при найме сотрудника на работу включают редприятия предпочитают устранять любые риски, при этом, существует правило, что абсолютное отсутствие рисков не менее вредит организации. Необходимо четко обозначить тот уровень риска, который приемлем для деятельности предприятия, а для определения санкций к различным рискам, необходимо сопоставить риски предприятия в целом и риски в системе управления персоналом. Задача минимизации рисков в системе управления персоналом обусловлена важнейшей ролью человеческого фактора в функционировании предприятия.

Риск является совокупностью вероятности и последствий наступления негативных событий, при этом риск не всегда связан с негативными последствиями, поскольку может привести и к положительным результатам, в виде прибыли или успешного проекта. Риски в системе управления персоналом - явление постоянное, имеющее место на этапе найма, при прохождении испытательного срока, в процессе работы и при увольнении работника. в себя ухудшение имиджа компании и финансовые потери, связанные с наймом неподходящего кандидата. Риск, связанный с ухудшением имиджа организации, может возникнуть по причине некорректного содержания и формы объявления о вакансии или из-за необученного персонала, уже работающего на предприятии.

Причинами риска подбора нерелевантного кандидата можно рассматривать переоценку его профессиональных качеств, недооценка предыдущего опыта работы, противоречие целей организации и личных целей соискателя, психологическая несовместимость с коллективом, слабая мотивация к работе; отсутствие на этапе подбора проверки соискателя [2].

Для минимизирования рисков при найме персонала, необходимо ужесточение проверки, начиная от контроля паспортных и анкетных данных или проверки подлинности документов об образовании и завершая использованием различных методов тестирования. 
Во время работы с персоналом, часто встречающимся риском является трансформация предприятия в кадрового поставщика обученных специалистов для своих же конкурентов. Причиной является в неполной мере разработанные системы мотивации сотрудников, отсутствие организованности в коллективе и т.п. Снизить данные риски можно с помощью продуманной системы мотивации, включающей не только материальные, но и нематериальные способы стимулирования, а также предоставление возможности профессионального роста.

Риски, обусловленные увольнением персонала, могут возникнуть в случае конфликтного увольнения сотрудника. Рисками для организации, при подобном развитии событий, могут быть как моральный ущерб предприятию в виде антирекламы, так и финансовые потери, при факте обращения уволенного работника в судебные инстанции.

Уменьшить риски поможет правильная организация процедуры увольнения. Работодателю необходимо объяснить сотруднику причины увольнения, грамотно прокомментировать ситуацию, что в результате такого решения обеим сторонам будет лучше, постараться сохранить контакт с работником после его ухода [3, с. 155].

Анализ рисков в сфере управления персоналом позволяет выявить факторы, оказывающие значительный отрицательный эффект на работу персонала и всего предприятия, что способствует нахождению оптимального решения для сохранения необходимого уровня вовлеченности и удовлетворенности работников, формирования профессиональных компетенций и увеличения эффективности труда.

Человеческий фактор значительно влияет на деятельность системы управления предприятием, на количество и виды потенциальных конфликтов, их частоту и способы разрешения, на уровень корпоративной культуры, на репутацию предприятия.

Как правило, рассмотренная группа рисков может быть минимизирована при помощи методов мониторинга и контроля, применения кадрового аудита, развития персонала, обеспечения условий для карьерного роста, создания алгоритмов подбора и найма работников, улучшения микроклимата в коллективе, повышении заинтересованности работника в длительном сотрудничестве [2].

В состоянии расширения экономических рисков на предприятии возрастает актуальность обеспечения ее кадровой безопасности. Система управления кадровой безопасностью призвана уберечь сотрудников предприятия от внешних и внутренних угроз, а также гарантировать защиту от рисков, обусловленных противоправной и дестабилизирующей деятельностью работников - воровством, мошенничеством, взяточничеством и др., утечкой информации (коммерческой тайны, персональных данных, служебных сведений).

Причиной противоправных поступков сотрудников эксперты называют невысокий уровень лояльности персонала, часто обусловленный деструктивными (токсическими) действиями менеджеров.

Положение кадровой безопасности предприятия непосредственно отражается на благонадежности персонала, обусловленной удовлетворенностью рабочим местом и руководством, его проактивности и вовлеченности. Удовлетворенность можно определить как состояние работника, которого в целом устраивает предприятие, условия труда (заработная плата, содержание трудовых функций и др.) и он не склонен подыскивать себе другую работу. Лояльностью принято считать такое состояние сотрудника, при котором он выражает верность компании, хорошо выполняет свои должностные обязанности, ему нравится, он согласен работать на предприятии длительное время. Лояльность предусматривает появление некоторого эмоционального компонента (в отличие от удовлетворенности).

В совокупности, состояние удовлетворенности, лояльности и проактивности (стремление работать с максимальной отдачей, выражать инициативность, ориентированную на улучшение работы, искать новые решения проблем и задач) обусловливают возникновение вовлеченности.

Следовательно, можно предположить, что эти четыре компонента формируют уровень благонадежности по отношению к предприятию и имеют с ней корреляционную связь [6] (рис. 1).

С другой стороны, уровень благонадежности обусловлен наличием кадровых угроз. Акцент следует поставить на рост в компаниях токсических практик управления персоналом. Токсический руководитель наносит серьезное негативное влияние на работников, группы и организации, исходя из своих рассогласованных личностных качеств и деструктивного поведения.

Воздействие токсического менеджмента на кадровую безопасность производственного предприятия, представляет собой объект изучения в рамках мониторингового исследования уровня лояльности и вовлеченности персонала, проводимого на протяжении нескольких лет А.Э. Федоровой и Л.В.Несовой, некоторые результаты которого представлены далее [6]. 


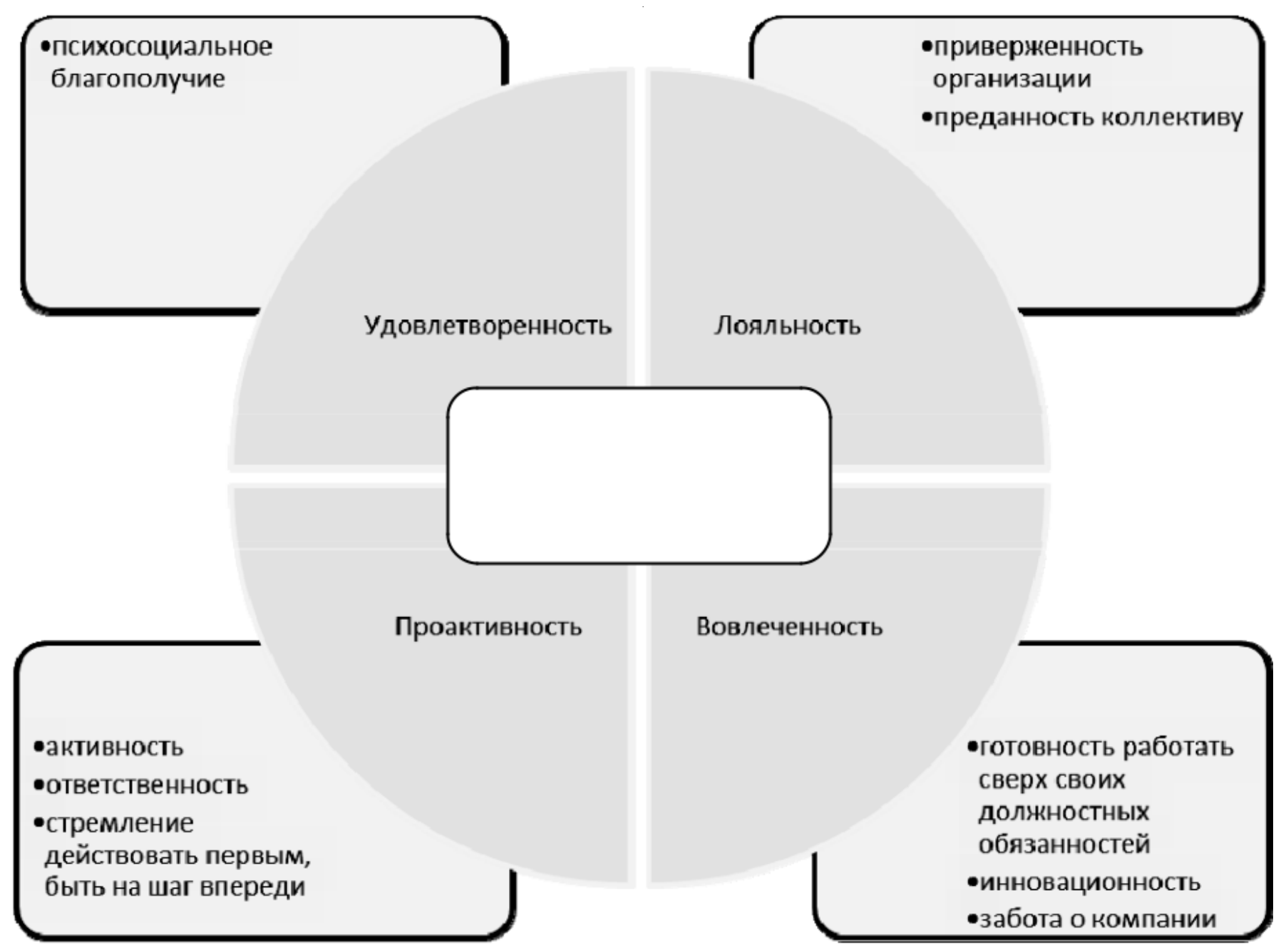

Рис. 1. Взаимосвязь между факторами благонадежности персонала организации

Проверка уровня лояльности и вовлеченности сотрудников крупного промышленного предприятия Уральского региона осуществляется ежегодно, на протяжении нескольких лет. В данной работе приведены некоторые результаты исследования за 20132015 гг. Целью разработки является установление причин внутриорганизационной среды, влияющих на степень лояльности, вовлеченности, надежности персонала и состояние кадровой безопасности предприятия.

В основе исследования лежит анонимное анкетирование работников предприятия. Количество респондентов несколько менялось на протяжении исследуемого периода, составив в 2013 г.- 1003 чел., в 2014 г.- 1490 чел., в 2015 г.- 1146 чел. (28,7, 42,6 и 32,7\% общего количества сотрудников данного предприятия).

В качестве способа оценки кадровых рисков на предприятии был выбран метод экспертных оценок, реали- зуемый способом обработки мнений опытных специалистов.

Экспертами для проведения данного анализа были выбраны: заместитель гендиректора по общим вопросам - 1 эксперт; специалист по кадровым вопросам - 2 эксперт; менеджер по подбору персонала - 3 эксперт.

В таблице 1 выведены итоги оценки кадровых рисков на промышленном предприятии. Балльная оценка кадрового риска распределялась экспертами в зависимости от вероятности его наступления: 0 - риск не существенен для предприятия; 25 - имеется незначительная вероятность появления риска; 50 - равная вероятность появления или не появления риска; 75 - имеется большая вероятность появления риска; 100 - риск определенно наступит.

Степень воздействия каждого риска определяется следующими значениями: 
Таблица 1. Результаты оценки кадровых рисков в промышленной организации

\begin{tabular}{|c|c|c|c|c|c|c|c|}
\hline \multirow[b]{2}{*}{ Риски } & \multicolumn{3}{|c|}{ Эксперты } & \multirow{2}{*}{$\begin{array}{l}\text { Средний } \\
\text { балл } \\
\text { оценки } \\
\text { рисков }\end{array}$} & \multirow[b]{2}{*}{$\begin{array}{l}\text { Степень } \\
\text { влияния }\end{array}$} & \multirow[b]{2}{*}{ Bec } & \multirow[b]{2}{*}{ Оценка } \\
\hline & 1 & 2 & 3 & & & & \\
\hline $\begin{array}{l}\text { Несбалансированность возрастных } \\
\text { групп персонала }\end{array}$ & 50 & 50 & 50 & 50 & 3 & 0,05 & 2,5 \\
\hline $\begin{array}{l}\text { Отсутствие мониторинга угроз } \\
\text { жизненно важных интересов } \\
\text { предприятия }\end{array}$ & 75 & 75 & 75 & 75 & 2 & 0,075 & 5,5 \\
\hline $\begin{array}{l}\text { Отсутствие мер по выявлению, } \\
\text { предупреждению и пресечению } \\
\text { действий, способных повлечь урон } \\
\text { интересам предприятия }\end{array}$ & 75 & 75 & 75 & 75 & 2 & 0,075 & 5,5 \\
\hline $\begin{array}{l}\text { Подбор персонала недостаточной } \\
\text { квалификации }\end{array}$ & 75 & 75 & 50 & 66,6 & 3 & 0,075 & 5 \\
\hline $\begin{array}{l}\text { Недостаточное количество } \\
\text { мероприятий для формирования } \\
\text { лояльности работников предприятия }\end{array}$ & 75 & 50 & 50 & 58,3 & 3 & 0,05 & 2,9 \\
\hline $\begin{array}{l}\text { Наличие конфликтов интересов } \\
\text { работников и работодателя }\end{array}$ & 50 & 75 & 50 & 58,3 & 3 & 0,05 & 2,9 \\
\hline $\begin{array}{l}\text { Отсутствие оценки различных } \\
\text { форм проявления нелояльности } \\
\text { и неблагонадежности работни- } \\
\text { ков организации }\end{array}$ & 50 & 75 & 75 & 66,6 & 2 & 0,075 & 5 \\
\hline Итого & & & & & & & 29,3 \\
\hline
\end{tabular}

1 - недопустимая степень воздействия, вес значения - 0,1 ;

2 - значительная степень воздействия, вес значения -0,075;

3 - средняя степень воздействия, вес значения 0,05

4 - приемлемая степень воздействия, вес значения $-0,01$.

Оценки экспертов были приведены к среднему значению, которое использовалось в дальнейших расчетах.

Как видно из таблицы 1, суммарное значение кадровых рисков на данном промышленном предприятии, составляет 29,3 балла, что представляет собой приемлемый показатель, в тоже время, выявляет слабые стороны в управлении персоналом [6].

Полученные результаты анализа деятельности промышленного предприятия показывают необходимость устранения следующих выявленных недостатков:

- отсутствие понимания вероятности проявления кадровых рисков при создании стратегических и тактических планов предприятия;

- не в полной мере разработан пакет внутренних локальных документов, фиксирующих основы и методы управления кадровыми рисками;
- отсутствие оформленного алгоритма выявления, анализа и оценки кадровых рисков;

- ограниченная эффективность действующих мероприятий по сокращению кадровых рисков;

- не в полной мере обозначены функции специалистов (локальные цели), не озвучены стратегические цели предприятия.

По итогам ежегодных исследований, проводимых на производственном предприятии, можно увидеть, что большая часть факторов, укрепляющих благонадежность работников, обусловлена проблемой эффективных коммуникаций. На практике, недостаток официальной информации заменяется слухами и догадками, поэтому встает проблема прозрачности и доступности информации для работников.

В целях устранения выявленных проблем рекомендовано ввести систему прозрачных коммуникаций, используемых как инструмент гарантии кадровой безопасности предприятия [3].

С целью обнаружения и минимизации рисков появления угроз кадровой безопасности, сделать регулярным контроль влияющих факторов, создавая условия, невыгодные для совершения неблагонадежных действий по отношению к предприятию. По этой причине важнейшее значение для организации имеет предупре- 


\section{КАДРОВЫЕ РИСКИ}
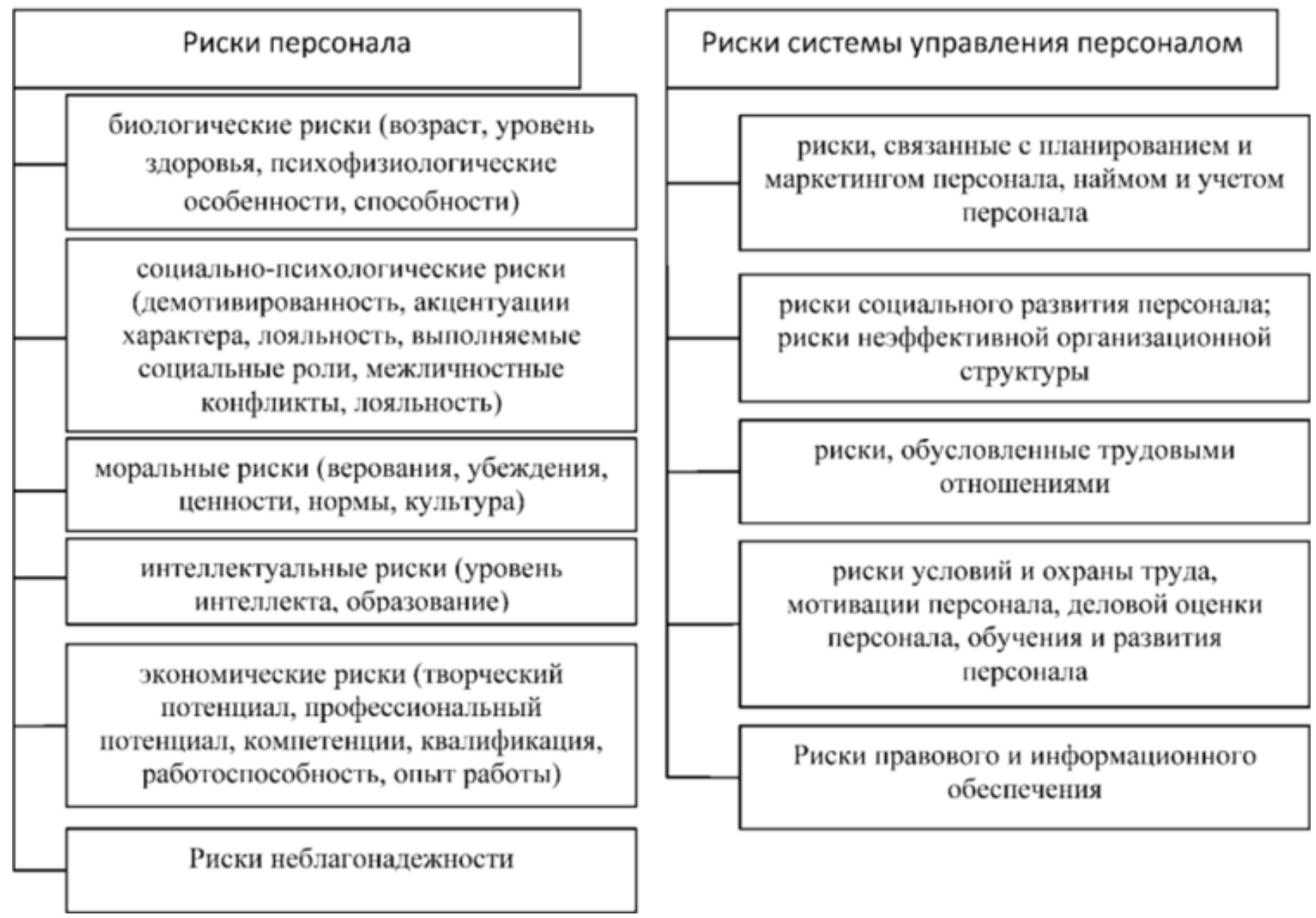

Рис. 2. Обобщенная схема кадровых рисков

ждающая и регулярная диагностика уровня лояльности и благонадежности сотрудников. Данная методика объединяет в себе потенциал обнаружения кадровых рисков и путей их сокращения для укрепления благонадежности работников, а внедрение предлагаемой системы прозрачных коммуникаций даст возможность администрации исследуемого промышленного предприятия способствовать эффективности информационного обеспечения сотрудников, снижая кадровые риски и укрепляя кадровую безопасность компании [1, c. 41].

Стратегической задачей промышленной организации в области управления персоналом является формирование высококвалифицированного и мобильного кадрового резерва. Современная цель менеджеров по управлению персоналом представляет собой модернизацию и улучшение качества подготовки, переподготовку и повышение мастерства персонала, со- вершенствование инструментов оценки деятельности и мотивации, стимулирования трудовых процессов сотрудников, разработка самообучающейся организационной среды, формирование благоприятного социально-психологического климата.

Главным противоречием в формировании и реализации стратегии управления кадровыми рисками является недостаточная проработка стратегии, с учетом целостной системы кадрового менеджмента промышленного предприятия.

Заключение. На фоне актуализации процедуры продвижения кадровой политики предприятия, увеличивается роль системы контроля кадровых рисков, как средства повышения продуктивности и плодотворности труда персонала. Риски в управлении персоналом представляют собой неотъемлемую часть функционирования любого предприятия и могут появиться на любом 
этапе этого управления. Возникающие кадровые риски в системе управления персоналом показывают рост ценности человеческого фактора и эффективности системы менеджмента в решении стратегических вопросов промышленных предприятий.

Кадровые риски на предприятии могут обнаруживаться разными способами:

- несоблюдение сотрудниками трудовой дисциплины и принятых правил поведения;

- увеличение уровня неплодотворной конфликтности и стрессогенности в среде сотрудников предприятия;

- недостаточно эффективная организационная структура;

- слабый уровень профессиональной квалификации работников;

- рост текучести кадров;

- финансовый урон (мошенничество);

- угрозы информационной безопасности;

- риски утраты репутации;
- невосприимчивость сотрудников к нововведениям;

- риски несоблюдения трудового законодательства и пр.

Регулирование кадровыми рисками на предприятии заключается в их выявлении, идентификации и оценке. Требуется осуществление классификации кадровых рисков, с целью оценки экспертом (менеджером по персоналу) место каждого риска в общей системе, для выбора эффективных методов управления рисками, модернизации кадровой политики и стратегического развития промышленного предприятия.

Основным научным результатом исследования можно определить систематизированную рекомендацию по управлению риском коммуникаций на базе концепции превентивного риск-менеджмента. Знание основных источников риска предоставляют возможность прогнозировать деятельность, учитывая возможные угрозы, и выбирать адекватные меры реагирования на них.

\section{ЛИТЕРАТУРА}

1. Гатти М., Федорова А. Э. Токсические элементы корпоративных социально-трудовых отношений: рабочее место, руководство и персонал // Вестн. Ом. ун-та. Сер. «Экономика».— 2014.— № 2.—C. 46-51.

2. Минеева Н.С. Риски в системе управления персоналом// Наука и образование сегодня.2017.№ 12(23). URL: https://cyberleninka.ru/article/n/riski-v-sistemeupravleniya-personalom (дата обращения 25.05.2020)

3. Родина Л. А. Управление рисками коммуникаций на промышленных предприятиях// Вестник Омского университета. Серия «Экономика».2018.№ 2. URL: https://cyberleninka.ru/article/n/upravlenie-riskami-kommunikatsiy-na-promyshlennyh-predpriyatiyah (дата обращения 25.05.2020)

4. Слободской А. Л. Риски в управлении персоналом: учеб. пособие / под ред. В. К. Потемкина.—СПб.: Изд-во СПбГУЭФ, 2011.— 155 с.

5. Федорова А. Э. Реализации элементов управления рисками бизнес-процессов в стандартах на системы менеджмента промышленного предприятия // Известия ВУЗов. Поволжский регион. Общественные науки. 2015. № 2 (34). URL: https://cyberleninka.ru/article/n/predposylki-realizatsii-elementov-upravleniyariskami-biznes-protsessov-v-standartah-na-sistemy-menedzhmenta-promyshlennogo (дата обращения: 25.05.2020).

6. Федорова А.Э., Л. В. Несова Л. В. Исследование кадровых рисков и факторов благонадежности персонала промышленного предприятия// ЖуРНАЛ Вестник Омского университета. Серия «Экономика».2017.№ 4.URL: https://cyberleninka.ru/article/n/issledovanie-kadrovyh-riskov-i-faktorov-blagonadezhnostipersonala-promyshlennogo-predpriyatiya (дата обращения 25.05.2020)

(c) Крюков Алексей Анатольевич ( alexeykryukov@yandex.ru ).

Журнал «Современная наука: актуальные проблемы теории и практики» 